\title{
Genetic variations among selected wild Asian elephant populations in Peninsular Malaysia based on mitochondrial D-loop region DNA sequences
}

\author{
KAYAL VIZI KARUPPANNAN ${ }^{1,2, \bullet}$, NOR RAHMAN AIFAT ${ }^{2}$, KHAIRUL AMIRIN MOHAMED ${ }^{1}$, \\ NURUL FARAH DIYANA AHMAD-TAHIR ${ }^{1}$, FATIN MARDHIAH NORDIN ${ }^{2}$, SALMAH YAAKOP ${ }^{2}$, \\ JESÚS E MALDONADO ${ }^{3}$, BADRUL MUNIR MD-ZAIN ${ }^{2, \bullet \bullet}$ \\ ${ }^{1}$ Department of Wildlife and National Parks (DWNP) Peninsular Malaysia. Km 10 Jalan Cheras, 56100 Kuala Lumpur, Malaysia.`email: \\ kayalvizi@wildlife.gov.my \\ ${ }^{2}$ School of Environmental and Natural Resource Sciences, Faculty of Science \& Technology, Universiti Kebangsaan Malaysia. 43600 Bangi, Selangor, \\ Malaysia."vemail: abgbadd@ukm.edu.my, abgbadd1966@yahoo.com \\ ${ }^{3}$ Smithsonian Conservation Biology Institute, Center for Conservation Genomics National Zoological Park, 3001 Connecticut Ave NW, Washington DC., \\ United States of America
}

Manuscript received: 26 July 2019. Revision accepted: 14 August 2019.

\begin{abstract}
Karuppannan KV, Aifat NR, Mohamed KA, Ahmad-Tahir NFD, Nordin FM, Yaakop S, Maldonado JE, Md-Zain BM. 2019. Genetic variations among selected wild Asian elephant populations in Peninsular Malaysia based on mitochondrial D-loop region DNA sequences. Biodiversitas 20: 2494-2502. Asian elephant (Elephas maximus) is an important large mammal in Peninsular Malaysia and is completely protected by the Wildlife Conservation Act 2010 (Act 716). The conservation of this species requires strong informationbased research, such as genetic evaluations. The aim of this study was to compare mitochondrial control region variation among selected elephants from the Taman Negara National Parks (TNNP) population with other selected populations in Peninsular Malaysia. DNA materials were extracted from fecal samples and amplified using partial mitochondrial D-loop region. Total 13 haplotypes with haplotype diversity (Hd) of 0.7524 were observed. A total of 34 base pair (bp) segregation sites were formed in 547 bp sequences. Both phylogenetic trees showed that a few individual elephants from the TNNP formed a clade together with individuals from other populations. The remaining individual elephants from TNNP formed a monophyletic clade supported by a high bootstrap value. Low genetic distance was detected among the tested populations, which proved that both individuals from the TNNP and other selected populations have similar genetic patterns. High gene flow among tested populations would impact on fitness and long-term resilience of the populations. This highly significant outcome provides strong baseline data for Department of Wildlife and National Parks (DWNP) in monitoring elephant populations in order to reduce number of human-elephant conflicts which indirectly minimize translocating conflict elephants to TNNP.
\end{abstract}

Keywords: Asian elephant, Elephas maximus, Taman Negara National Parks, haplotype, conservation

\section{INTRODUCTION}

The Asian elephant (Elephas maximus) is one large mammal flagship species in Peninsular Malaysia (Abd Rasid et al. 2019). Asian elephants have high ecological importance and are prioritized by the Department of Wildlife \& National Parks (DWNP) as the wildlife managing authority. This large mammal is a completely protected species under the Wildlife Conservation Act 2010 (Act 716) and is classified as "Vulnerable" under the Red List of mammals (PERHILITAN 2017). Globally, the current population trend of E. maximus is declining due to habitat loss and human-elephant conflict caused by expanding human populations and poaching (Choudhury et al. 2008). Appropriate and effective conservation mitigation strategies must be addressed to protect this mammal. Continuous research activities used to monitor the elephant population size and trends are needed as part of adaptive management action to conserve Asian elephants (Asian Elephant Conservation Act 1997; Fernando and Leimgruber 2011).
In Peninsular Malaysia, the management and conservation plans of Asian elephants are stipulated in the National Elephant Conservation Action Plan (NECAP) in line with the National Policy on Biological Diversity and National Policy on the Environment (NECAP 2013). One of the long-term goals of the NECAP is to better understand the biology of elephants, such as their populations, ecology, habitat suitability and genetic assessment via evidence-based research activities. In Peninsular Malaysia, the current geographical distribution of elephants in priority conservation areas, such as protected areas, is not accurately known due to a lack of comprehensive research, such as molecular genetic evaluations among wild elephant populations (Salman et al. 2011; Sripiboon 2013). Genetic management can help to manage the Asian elephant population in long term since molecular tools have been used to estimate genetic variability within and among wild populations (Okello et al. 2008; Goossens et al. 2016: Kusza et al. 2018), identify genetically distinct evolutionary significant units (Moßbrucker et al. 2015), guide and evaluate the success of 
wildlife translocations (Okello et al. 2008; Goldenberg et al. 2019), study social organization integrity (Nyakaana et al. 2001), estimate activity pattern, population size and sex ratio of elusive animals (Ahlering et al. 2011; Md-Zain and Ch'ng 2011) and to identify human-wildlife conflicts (Mondol et al. 2009; Md-Zain et al. 2010a).

There are several approaches to conducting genetic evaluations among wild elephants, including an assessment by maternal lineages based on mitochondrial DNA (mtDNA) variation. The outcomes from mtDNA-based studies can estimate phylogenetic diversity among studied species and are an important element in tracing evolutionary relationships within populations (Fernando et al. 2000; Fleischer et al. 2001; Fernando et al. 2003). A previous study by Elliza et al. (2015) demonstrated a haplotype pattern among 21 Asian elephants of Peninsular Malaysia using the highly variable D-loop region of mtDNA. The outcome showed low genetic variation among tested samples; however, the 21 samples did not include elephants from Taman Negara National Parks (TNNP), which has the largest population of Asian elephants from Peninsular Malaysia.

The current study was designed to evaluate the Malay Peninsular Asian elephant genetic structure by incorporating additional TNNP samples into previous molecular data (Elliza et al. 2015). MtDNA was selected as a candidate marker due to its application to systematic, population genetics and phylogeography issues (Md-Zain et al. 2010b; Zainudin et al. 2010; Abdul-Latiff et al. 2019). It was anticipated that the outcome would reveal a stronger phylogenetic variation pattern among elephants of Peninsular Malaysia as a source of important population genetic information for NECAP (NECAP 2013). This information is important for designing future conservation approaches and for improvising current mitigations for Asian elephants in Peninsular Malaysia.

\section{MATERIALS AND METHODS}

\section{DNA extraction, PCR, and sequencing}

Fecal samples of Asian elephant collected from Taman Negara National Parks (TNNP) in Peninsular Malaysia were extracted using the QIAamp DNA Stool Mini Kit (QIAGEN, Germany) (Table 1, Figure 1). The extractions were performed according to the protocol given by the manufacturer. The quantification of nucleic acids was conducted using a NanoDrop 2000 Spectrophotometer (Thermo Fisher Scientific, Singapore). All available sequences of different elephant's ranges were retrieved from Elliza et al. (2015) for comparative analysis purposes. Mammuthus primigenius which is the nearest species to the ingroup was chosen as an outgroup.

DNA amplification using Polymerase Chain Reaction (PCR) was performed with PCR optimization (Rosli et al. 2011) using the mitochondrial control region (Table 2) (Fernando et al. 2000). PCR was performed using Master Mix Promega (Promega, United States) with the following cocktail: $11 \mu \mathrm{L}$ Master Mix Promega, $10 \mu \mathrm{L}$ of ddh2O, 1 $\mu \mathrm{L}$ each of $10 \mu \mathrm{M}$ primers, and $2 \mu \mathrm{L}$ of template DNA.
The three-step PCR was performed under the following conditions: Pre-denaturation at $95^{\circ} \mathrm{C}$ for $10 \mathrm{~min}, 45$ cycles of denaturation at $95^{\circ} \mathrm{C}$ for $1 \mathrm{~min}$, annealing at $60-63^{\circ} \mathrm{C}$ for $1 \mathrm{~min}$, extension at $72^{\circ} \mathrm{C}$ for $1 \mathrm{~min}$, and a final extension of $10 \mathrm{~min}$ at $72^{\circ} \mathrm{C}$ with further optimization. DNA purification was performed to obtain a successful amplification product. This process was performed using ExoSAP-IT following the manufacturer's protocol. The purified PCR products were sent to Apical Scientific Sdn. Bhd laboratory (Malaysia) for sequencing.

\section{Sequencing and data analysis}

The raw sequences were obtained and edited using Geneious version 10.1.3 (Biomatters Ltd. 2017) as well as pairwise and multiple sequence alignments. The edited sequence was blasted through GenBank BLASTn for the sequence similarity searches analysis (Aifat et al. 2016; Abdul-Latiff et al. 2017). All the DNA sequences were aligned together with previous data (Elliza et al. 2015) using MEGA 7 (Kumar et al. 2016). MEGA 7 and DnaSP 6 (Rozas et al. 2017) were used as software in the sequence analysis, which focused on genetic distance, haplotype diversity, unique haplotypes, and phylogenetic trees. The phylogenetic relationships of each detected haplotype in elephants were mapped through a minimum-spanning network (MSN) using Network 5.0.

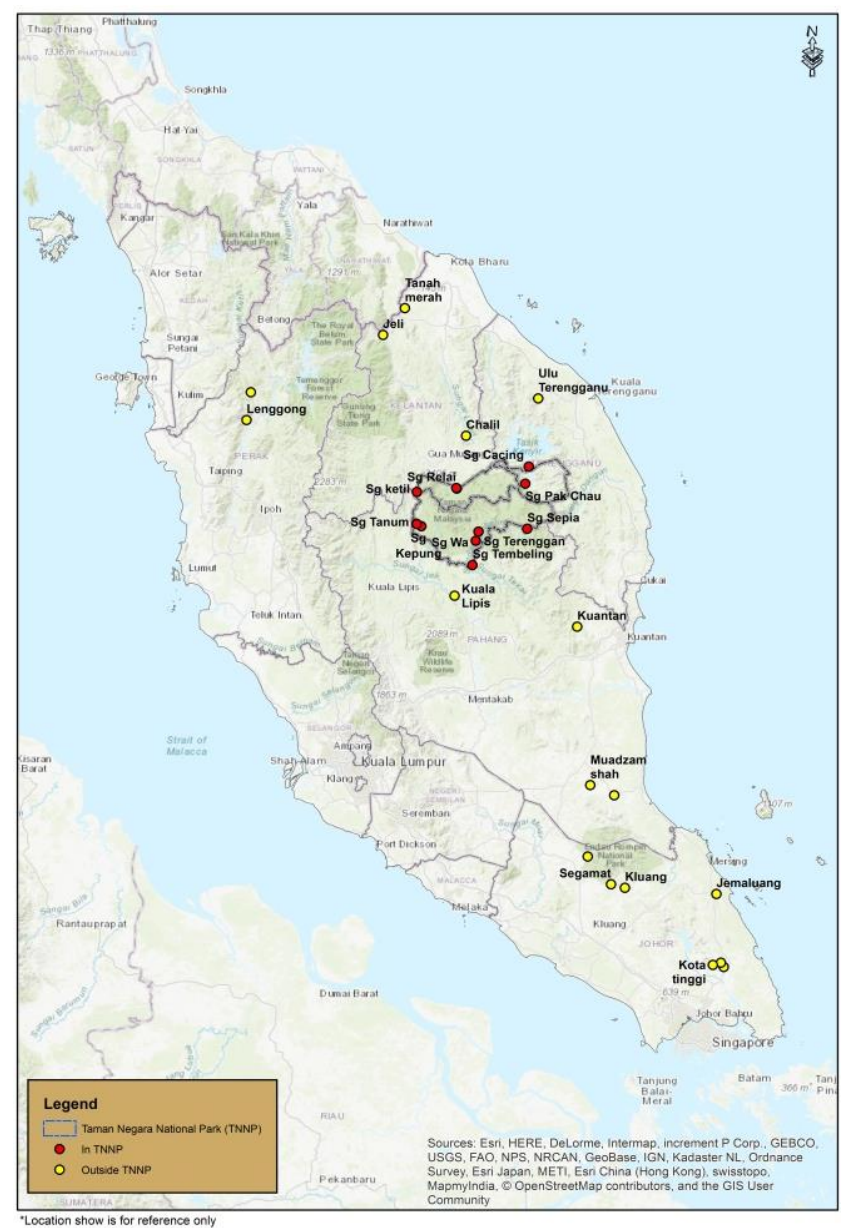

Figure 1.The map of elephant's ranges in this study. The red dot indicates the location of TNNP's samples, and the yellow dot indicates the location from a previous study (Elliza et al. 2015) 
Table 1. Details on samples and sequences used in this study

\begin{tabular}{|c|c|c|}
\hline $\begin{array}{l}\text { Sample } \\
\text { code }\end{array}$ & Location & Reference \\
\hline TN551 & TNNP Sg. Pak Chau, Kelantan & This study \\
\hline TN552 & TNNP Sg. Pak Chau, Kelantan & This study \\
\hline TN559 & TNNP Sg. Relai, Terengganu & This study \\
\hline TN560 & TNNP Sg, Relai, Terengganu & This study \\
\hline TN561 & TNNP Sg. Relai, Terengganu & This study \\
\hline TN562 & TNNP Sg. Relai, Terengganu & This study \\
\hline TN564 & TNNP Sg. Relai, Terengganu & This study \\
\hline TN565 & TNNP Sg. Ketil, Terengganu & This study \\
\hline TN568 & TNNP Sg. Tembeling, Terengganu & This study \\
\hline TN573 & TNNP Sg. Sepia, Pahang & This study \\
\hline TN585 & TNNP Sg. Terenggan, Pahang & This study \\
\hline TN589 & TNNP Sg. Wa, Pahang & This study \\
\hline TN590 & TNNP Sg. Wa, Pahang & This study \\
\hline TN591 & TNNP Sg. Kepung, Pahang & This study \\
\hline TN596 & TNNP Sg. Tanum, Pahang & This study \\
\hline TN597 & TNNP Sg. Tanum, Pahang & This study \\
\hline TN598 & TNNP Sg. Tanum, Pahang & This study \\
\hline TN622 & TNNP Sg. Cacing, Kelantan & This study \\
\hline TN623 & TNNP Sg. Cacing, Kelantan & This study \\
\hline E007 & Jeli, Kelantan & Elliza et al. (2015) \\
\hline E008 & Chalil, Kelantan & Elliza et al. (2015) \\
\hline E009 & Jemaluang, Johor & Elliza et al. (2015) \\
\hline E010 & Segamat, Johor & Elliza et al. (2015) \\
\hline E011 & Kuantan, Pahang & Elliza et al. (2015) \\
\hline E012 & Kluang, Johor & Elliza et al. (2015) \\
\hline E013 & Kota Tinggi, Johor & Elliza et al. (2015) \\
\hline E014 & Kota Tinggi, Johor & Elliza et al. (2015) \\
\hline E015 & Kota Tinggi, Johor & Elliza et al. (2015) \\
\hline E022 & Kuala Lipis, Pahang & Elliza et al. (2015) \\
\hline E023 & Lenggong, Perak & Elliza et al. (2015) \\
\hline E024 & Muadzam Shah, Pahang & Elliza et al. (2015) \\
\hline E025 & Muadzam Shah, Pahang & Elliza et al. (2015) \\
\hline E026 & Hulu Terengganu, Terengganu & Elliza et al. (2015) \\
\hline E027 & Lenggong, Perak & Elliza et al. (2015) \\
\hline E028 & Tanah Merah, Kelantan & Elliza et al. (2015) \\
\hline E029 & Segamat, Johor & Elliza et al. (2015) \\
\hline
\end{tabular}

Table 2. Primer sequence of the partial D-loop region (Fernando et al. 2000)

\begin{tabular}{ll}
\hline Primer & Sequence (5'- 3') \\
\hline MDL3 (Forward) & CCC ACA ATT AAT GGG CCC GGA GCG \\
MDL5 (Reverse) & TTA CAT GAA TTG GCA GCC AAC CAG \\
\hline
\end{tabular}

The phylogenetic analysis was performed based on two distinct criteria, namely distance-based (Neighbor-Joining, NJ) and character-based (Maximum Parsimony, MP). The NJ tree was constructed using the Kimura-2-Parameter model algorithm with 1000 bootstrap replications (SyedShabthar et al. 2013). The MP tree was constructed using Tree Bisection-Reconnection (TBR) with a heuristic searching method, and 1000 random stepwise additions were applied to identify the best MP tree. As for NJ, the MP tree was also tested with 1000 bootstrap replications.

\section{RESULTS AND DISCUSSION}

\section{Sequence polymorphism and genetic distance}

A total of 19 samples were successfully extracted and amplified with the targeted locus. The alignment of all these samples with reference sequences yielded sequences at a size of $547 \mathrm{bp}$ with 41 variable sites in which 11 sites were parsimony-informative characters. The pairwise genetic distance (Table 3) of the partial D-loop sequences was calculated in PAUP 4.0b10 (Swofford 2002) using the Kimura-2-Parameter model. The highest value between elephants in TNNP and other populations was 0.034, which was between TN562 with E010 and E026, while the minimum value was 0.000 . The range of genetic distance for each individual in TNNP was 0.000 to 0.037 . For the outgroup, the distance from each ingroup showed the minimum value of genetic distance of 0.034 , and the maximum value was 0.047 .

\section{Phylogenetic trees}

The NJ phylogeny tree (Figure 2) was generated using Kimura-2-Parameter with 1000 bootstrap replications and showed that a few samples from TNNP form a clade together with other populations. These samples are TN551, TN552, TN585, TN596, TN597, TN598, and TN622. The formation of the clade was supported by a $60 \%$ and a $43 \%$ bootstrap value. TN562, which was from Sg. Relai, Terengganu, formed a monophyletic clade with Clade A supported by a $51 \%$ bootstrap value. The remaining samples of TNNP formed one clade together supported by a $97 \%$ bootstrap value. The MP tree (Figure 3) was reconstructed with a consistency index $(\mathrm{CI})=0.6875$, retention index $(\mathrm{RI})=0.9468$, and tree length $=32$. Seven samples from TNNP (TN551, TN552, TN585, TN596, TN597, TN598, and TN622) formed polytomy with individuals from other populations supported by a $69 \%$ bootstrap value. The sample from Hulu Terengganu (E026) formed together with the remaining samples from TNNP, which was supported by a low bootstrap value (43\%).

\section{Haplotype and Minimum-Spanning Network (MSN)}

The D-loop region analyses successfully yielded 13 haplotypes of TNNP and other populations with haplotype diversity $(\mathrm{Hd})=0.7524$. A total of $34 \mathrm{bp}$ segregation sites were formed in $547 \mathrm{bp}$ (Table 4). Almost all of E. maximus in this study shared the same haplotype, which was Hap 1, except for the sample from Hulu Terengganu (E026). E026 was represented by Hap 4. Hap 2 and Hap 3 were comprised of the population from Kelantan. Hap 5 was comprised of the population from Pahang. Hap 6, Hap 7, Hap 8, and Hap 9 were comprised of the population from Johor. The population from TNNP was represented by Hap 1 and Hap 10 to Hap 13. The MSN of the haplotypes (Figure 4) visualized the relationships between E. maximus from TNNP and other populations. The population from Hulu Terengganu was closer to the population from TNNP (Hap 10, 12 and 13) with seven mutation steps. A total of 16 samples shared Hap 1 from TNNP (7 samples), Perak (2 samples), Johor (3 samples), Pahang (3 samples), and Kelantan (1 sample). 
Table 3. Pairwise genetic distance of E. maximus with the outgroup

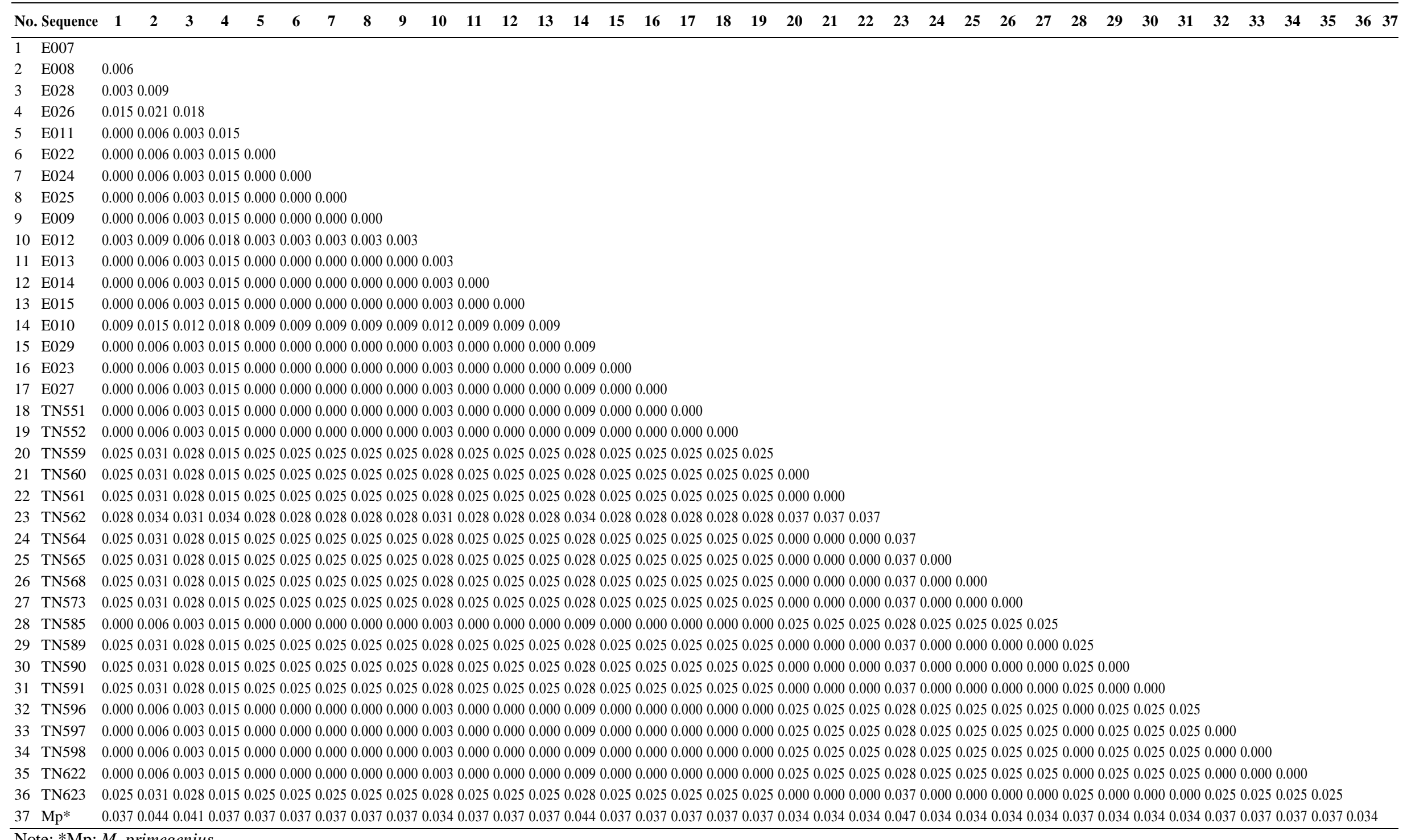




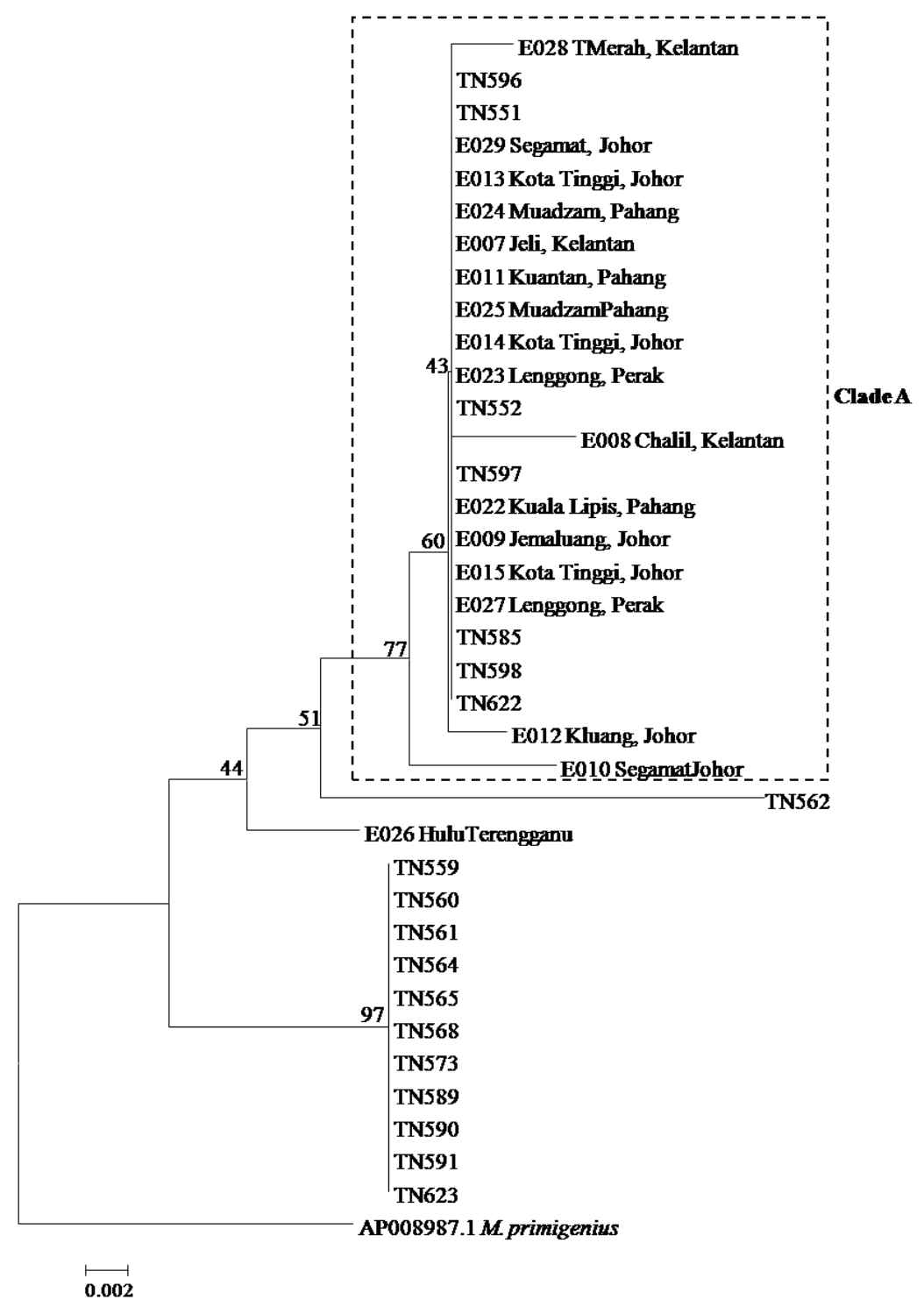

Figure 2. Neighbor-Joining (NJ) phylogenetic tree using the Kimura-2-Parameter algorithm with bootstrap values indicated on the branch

Table 4. Segregating sites ( $34 \mathrm{bp})$ in the $547 \mathrm{bp}$ segment of Dloop defining 13 haplotypes

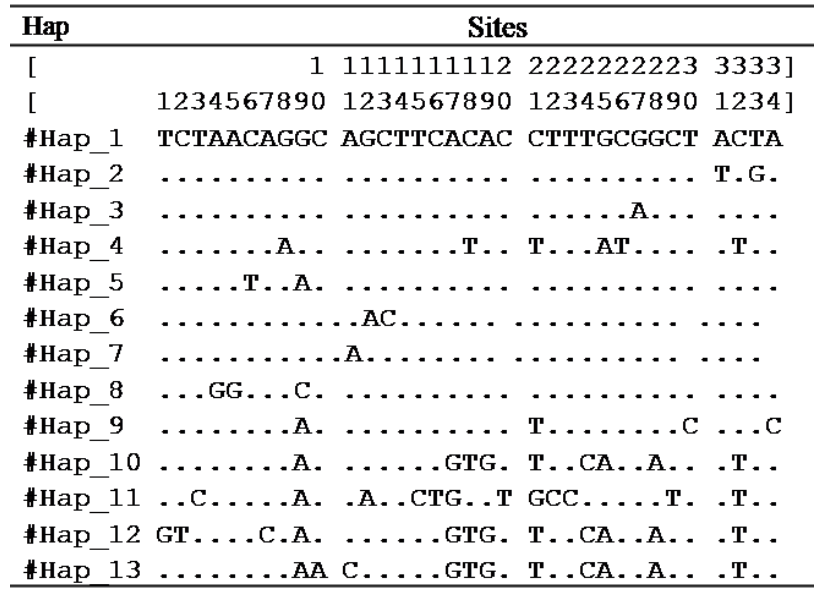

\section{Discussion}

In this study, a comparison of mitochondrial sequence variations among Asian elephant populations in Malay Peninsular was conducted, which indicated that TNNP possessed a $7.5 \%$ sequence polymorphism of a total of 547 bp. This variation was higher than that found by Elliza et al. (2015), who observed a $4.6 \%$ sequence when comparing individuals from five elephant range states in Peninsular Malaysia, which indicated a low genetic divergence among that population; however, a low genetic distance was $(<$ 0.5 ) observed between TNNP and other populations, which indicates that both groups were genetically identical. This outcome was not surprising because previous studies by Fernando et al. (2003) and Rutten (2008) found matching haplotypes among Thailand and Peninsular Malaysia populations, which indicates that Asian elephants can move for long distances. Thus, a similar scenario could have occurred in the current study due to the geographical factor. 


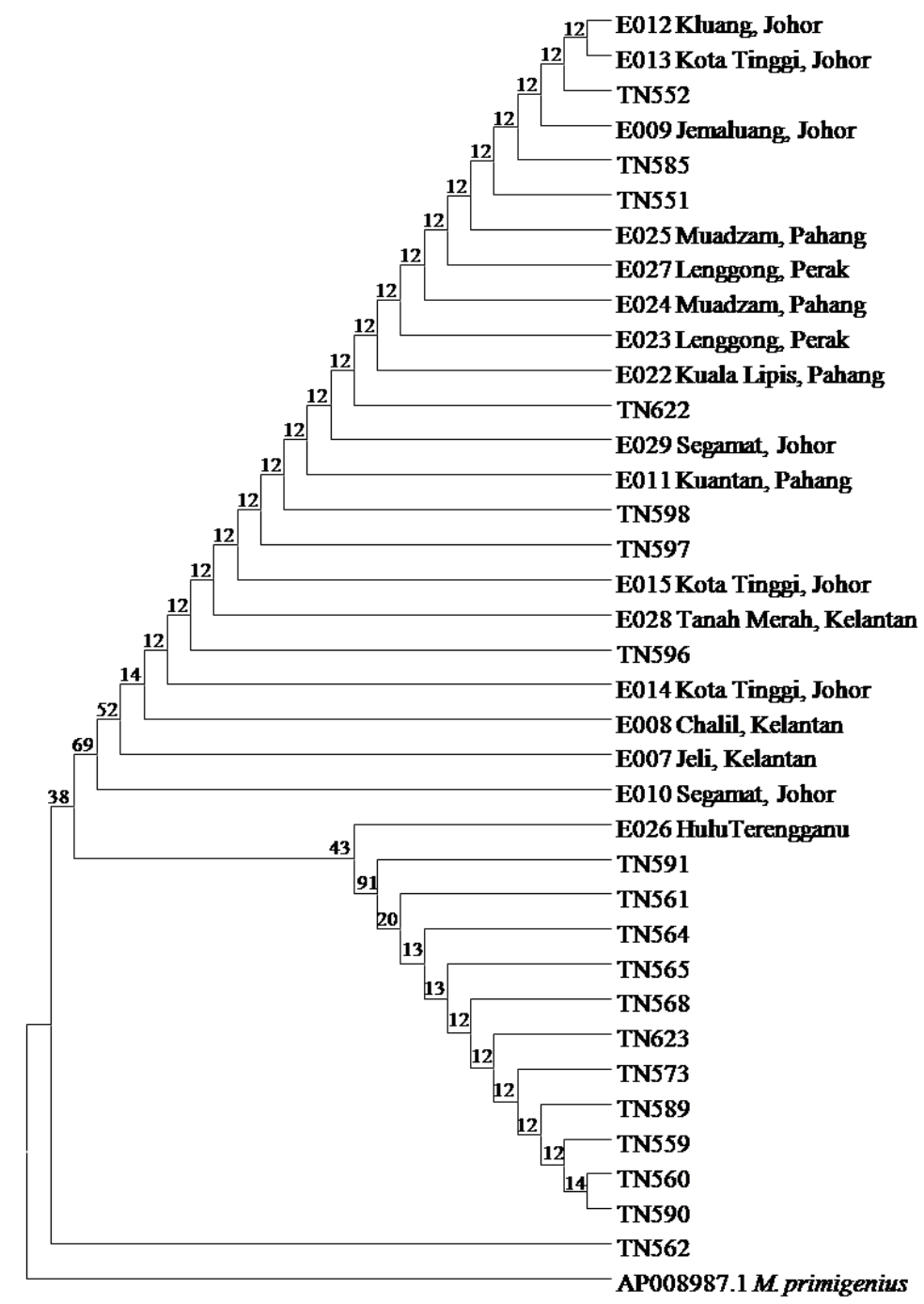

Figure 3. Maximum parsimony (MP) tree of E. maximus. Bootstrap values are indicated on the branch

Previous studies by Elliza et al. (2015) showed 10 haplotypes with a haplotype diversity $(\mathrm{H})$ of 0.830 . They found that the majority of tested wild elephants in Peninsular Malaysia shared haplotypes. Based on Elliza et al. (2015), it was assumed all 13 haplotypes with haplotype diversity $(\mathrm{H}=0.7524)$ in the current comparison would show a similar pattern of haplogroups; however, Hap 10, 12 , and 13 were only shared by TNNP populations, and Hap 4 was shared solely by wild elephants of Hulu Terengganu, which indicates close relationships with the TNNP groups. This implies the possibilities that elephant groups from Terengganu and the majority of TNNP elephants do not share a maternal line with other populations and remain a closed population. A similar scenario was observed in both the NJ and MP phylogenetic trees. The NJ and MP trees showed a significant separation from the woolly mammoth ( $M$. primigenius) as the outgroup. In the NJ tree, a separate clade from TNNP was formed with a $97 \%$ bootstrap value, while clade A was formed by combinations of 16 elephants of other populations with only seven elephants from the TNNP population. Both trees showed that there was a significant genetic difference among some elephants from the TNNP and other population samples originating from Hulu Terengganu. 


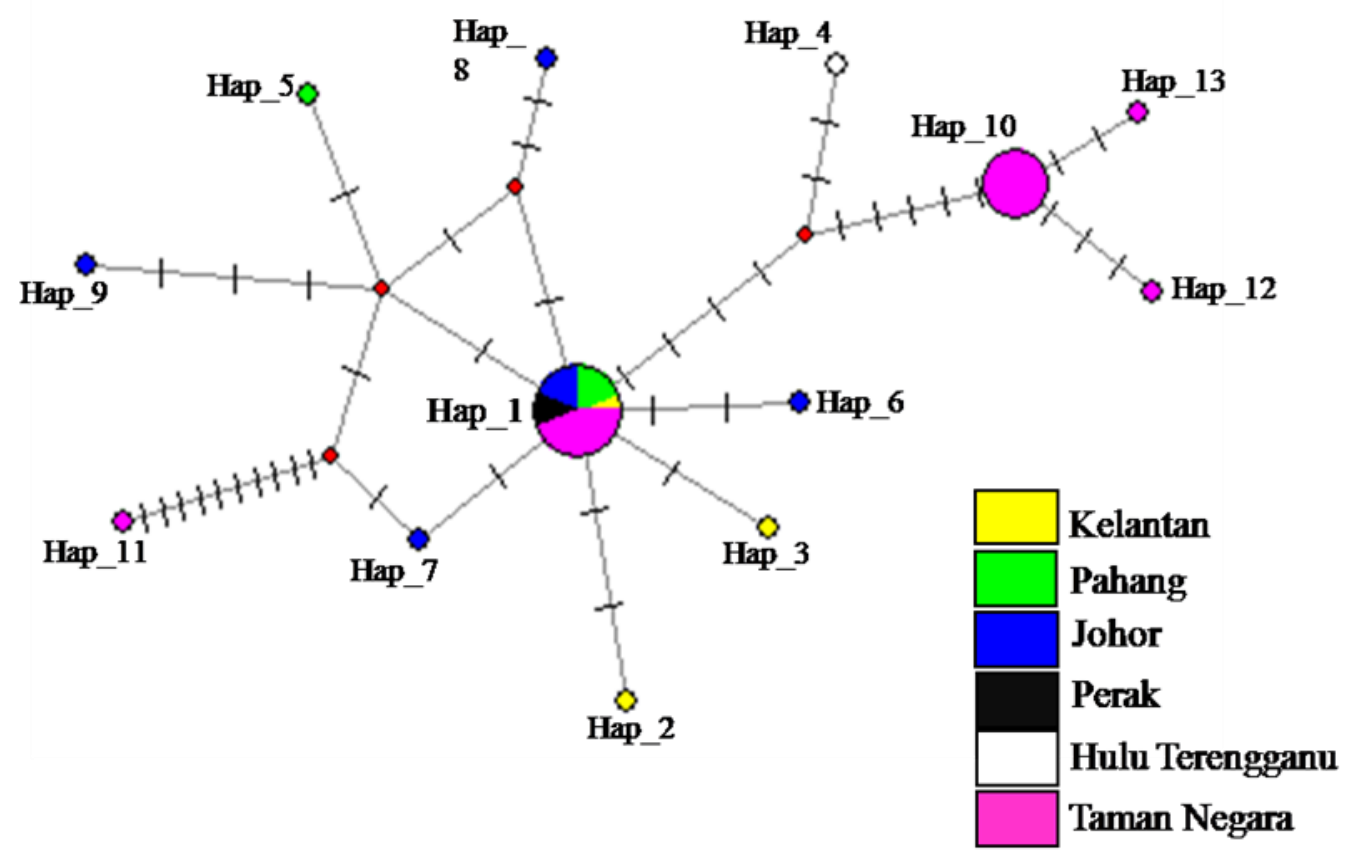

Figure 4. The minimum-spanning network (MSN) illustrating haplotype relationships of E. maximus. Red nodes represent the median vector, which is a hypothesized often as an ancestral sequence

There are some ecological aspects that likely can explain the outcomes of this comparison study. Currently, there are six states in Peninsular Malaysia known as elephant range states and protected areas. The population of E. maximus in TNNP is among the main elephant populations because it is the oldest and largest protected area with approximately $4343 \mathrm{~km}^{2}$ of the area is covered with primary forest (Salman et al. 2011; NECAP 2013). In addition, since 1983, TNNP has been the priority release area for translocating Asian elephants involved in humanelephant conflicts. Conflicts occur in all elephant range states, and Elliza et al. (2015) showed that samples belong to these states as well as that high gene flow between elephants from outside and within TNNP is possible. Elephants are from matriarchal families (Nandini et al. 2018), and the percentage of matching haplotypes among these individuals would be high. Anthropogenic disturbances such as deforestation and wildlife habitat loss would increase human-elephant conflict indirectly thus promoting elephant translocation. Continuation of elephant translocation will reduce genetic fitness among these wild elephant populations and affect their social organization (Gray et al. 2014; Goossens et al. 2016). Habitat enrichment activities in elephant range habitats are possible to control conflicts and indirectly improve genetic flow among wild elephant populations (Salman et al. 2011).

The natural movement habits of Asian elephants imply a current genetic variation pattern. Elephants always prefer high water and food source areas for survival (Salman et al. 2011) and tend to move further away from one particular habitat. Magintan et al. (2016) found that during hydroelectric dam construction in Hulu Terengganu, the movement patterns of GPS-collared male and female elephants were similar; however, the home-range area of males was larger than that of females because the males roamed deeper into the forest. Few sampling sites examined by Elliza et al. (2015) were located nearer to TNNP. Thus, the migration of elephants into TNNP is possible via connected forests (Jamie et al. 2018).

In conclusion, the aim of this study was achieved by displaying the genetic variation of TNNP elephant population with other populations in Peninsular Malaysia. The genetic assessment plays an important role in Asian elephant conservation mitigations in Peninsular Malaysia. To avoid threats, such as the loss of genetic diversity among wild elephant populations, the maximum number of samples must be collected from TNNP and all elephant habitats, including state parks, such as the BelumTemenggor forest complex and the Endau-Rompin forest reserve, to evaluate Asian elephants' genetic variations. As a continuation of this research, a large number of elephant fecal samples from 32 sampling sites in TNNP were collected, and an evaluation of mitochondrial sequences will be carried out. The expected outcome will generally provide implications for the in situ and ex situ management of elephants in Peninsular Malaysia.

\section{ACKNOWLEDGEMENTS}

We are grateful to YBhg. Dato' Abdul Kadir bin Abu Hashim, Director General of the DWNP; Rahmat Topani, the Director of Conservation Ex-situ Division; Dr. Pazil 
Abdul Patah, the former Director of Conservation Biodiversity Division; Mr. Salman Hj. Saaban, former Director of Enforcement Division and Dr. Jeffrine Rovie Ryan Japning, Head of Research Section and finally Muhammad Munir Idris for their support during conducting this research activity. We are very thankful for Elephant Rescue Unit team for collecting precious samples with high risk in Taman Negara National Parks. We also expressed our gratitude to School of Environmental and Natural Resource Sciences, Faculty of Science \& Technology, Universiti Kebangsaan Malaysia (UKM) for providing great assistance. This study was funded by Grant UKM-ST-2016-012 and Fundamental Research Grant Scheme (FRGS/1/2016/STG05/NRE/1).

\section{REFERENCES}

Abdul-Latiff MAB, Aifat NR, Yaakop S, Md-Zain BM. 2017. A noninvasive molecular approach: exploiting species-locus-specific PCR primers in defeating numts and DNA cross-contamination of Cercopithecidae. J Anim Plant Sci 27:1015-1023.

Abdul-Latiff MAB, Baharuddin H, Abdul-Patah P, Md-Zain BM. 2019. Is Malaysia's banded langur, Presbytis femoralis femoralis, actually Presbytis neglectus neglectus? Taxonomic revision with new insights on the radiation history of the Presbytis species group in Southeast Asia. Primates 60: 63-79.

Abd Rasid S, Mohd Nawayai Y, Gumal M, Salman S, Ozia A, Cheong F, Shaari Z, Tyson M, Hedges S. 2019. Viability and management of the Asian elephant (Elephas maximus) population in the Endau Rompin landscape, Peninsular Malaysia. Peer J. DOI: $10.7287 /$ peerj.preprints. $27729 \mathrm{v} 1$

Ahlering MA, Hedges S, Johnson A, Tyson M, Schuttler SG, Eggert LS. 2011. Genetic diversity, social structure, and conservation value of the elephants of the Nakai Plateau, Lao PDR, based on noninvasive sampling. Conserv Genet 12: 413-422.

Aifat NR, Yaakop S, Md-Zain BM. 2016. Optimization of partial Cyt $b$ gene sequence from selected ancient Presbytis museum skin specimens. Malays Appl Biol 45: 93-96.

Asian Elephant Conservation Act of 1997. 1997. Available: https://www.fws.gov/international/pdf/multinational-speciesconservation-act-asian-elephant.pdf.

Choudhury A, Lahiri Choudhury DK, Desai A, Duckworth JW, Easa PS, Johnsingh AJT, Fernando P, Hedges S, Gunawardena M, Kurt F, Karanth U, Lister A, Menon V, Riddle H, Rübel A, Wikramanayake E. 2008. Elephas maximus. The IUCN Red List of Threatened Species 2008. IUCN SSC Asian Elephant Specialist Group,

Elliza MN, Shukor MN, Othman N, Md-Zain BM. 2015. Haplotype distribution among endangered Asian elephants (Elephas maximus) in Peninsular Malaysia. Malays Appl Biol 44: 129-135.

Fernando P, Pfrender ME, Encalada SE, Lande R. 2000. Mitochondrial DNA variation, phylogeography and population structure of the Asian elephant. Heredity 84: 362-372.

Fernando P, Vidya TNC, Payne J, Stuewe M, Davison G, Alfred RJ, Andau P, Bosi E, Kilbourn A, Melnick DJ. 2003. DNA analysis indicates that Asian elephants are native to Borneo and are therefore a high priority for conservation. PLoS Biol 1 (1): e6. DOI: 10.1371/journal.pbio.0000006

Fernando P, Leimgruber P. 2011. In the ecology and conservation of seasonally dry forests in Asia: Asian elephants and dry forests. Smithsonian Institution Scholarly, Washington, D.C.

Fleischer RC, Perry EA, Muralidharan K, Stevens EE, Wemmer CM. 2001. Phylogeography of the Asian elephant (Elephas maximus) based on mitochondrial DNA. Evolution 55: 1882-1892.

Gray TNE, Vidya TNC, Potdar S, Bharti DK, Sovanna P. 2014 Population size estimation of an Asian elephant population in eastern Cambodia through non-invasive mark-recapture sampling. Conserv Genet 15: 803-810

Goldenberg SZ, Owen MA, Brown JL, Wittemyer G, Oo ZM, Leimgruber P. 2019. Increasing conservation translocation success by building social functionality in released populations. Glob Ecol Conserv 18: e00604. DOI: 10.1016/j.gecco.2019.e00604.

Goossens B, Sharma R, Othman N, Kun-Rodrigues C, Sakong R, Ancrenaz M, Ambu LN, Jue NK, O’Neill RJ, Bruford MW, Chikhi L. 2016. Habitat fragmentation and genetic diversity in natural populations of the Bornean elephant: Implications for conservation. Biol Conserv 196: 80-92.

Jamie W, Hawthorne LB, Salman S, Nasharuddin O, Peter L, Arceiz AC. 2018. Why did the elephant cross the road? The complex response of wild elephants to a major road in Peninsular Malaysia. Biol Conserv 218: 91-98.

Kumar S, Stecher G, Tamura K. 2016. MEGA7: molecular evolutionary genetics analysis version 7.0 for bigger datasets. Mol Biol Evol 33: 1870-1874.

Kusza S, Suchentrunk F, Pucher H, Mar KU, Zachos FE. 2018. High levels of mitochondrial genetic diversity in Asian elephants (Elephas maximus) from Myanmar. Hystrix 29: 152-154.

Magintan D, Shukor MN, Lihan T, Ahmiza-Arceiz C, Salman S, Shahril MH, Ahmad MN. 2016. An assessment of elephant home ranges and movement patterns during construction of Hulu Terengganu hydroelectric dam, Terengganu using GPS satellite collars. AIP Conf Proc 1784: 060006. DOI: 10.1063/1.4966844

Md-Zain BM, Sha`ari NA, Mohd-Zaki M, Ruslin F, Idris NI, Kadderi MD, Idris WMR. 2010a. A comprehensive population survey and daily activity budget on long-tailed macaques of Universiti Kebangsaan Malaysia. J Biol Sci 10: 608-615.

Md-Zain BM, Lee SJ, Lakim M, Ampeng A, Mahani MC. 2010 b. Phylogenetic position of Tarsius bancanus based on partial Cytochrome $b$ DNA sequences. J Biol Sci 10: 348-354.

Md-Zain BM, Ch'ng CE. 2011. The activity patterns of a group of Cantor's dusky leaf monkeys (Trachypithecus obscurus halonifer). Intl J Zool Res 7: 59-67.

Mondol S, Navya R, Athreya V, Sunagar K, Selvaraj VM, Ramakrishnan U. 2009. A panel of microsatellites to individually identify leopards and its application to leopard monitoring in human-dominated landscapes. BMC Genet 10: 79. DOI: 10.1186/1471-2156-10-79.

Moßbrucker AM, Apriyana I, Fickel JR, Imron MA, Pudyatmoko S, Sumardi, Suryadi H. 2015. Non-Invasive Genotyping of Sumatran elephants: Implications for Conservation. Trop Conserv Sci 8: 745759 .

Nandini S, Keerthipriya P, Vidya TNC. 2018. Group size differences may mask underlying similarities in social structure: a comparison of female elephant societies. Behav Ecol 29: 145-159.

NECAP [National Elephant Conservation Action Plan]. 2013. Blueprint to Save Malaysia Elephants. National Elephant Conservation Action Plan, Kuala Lumpur.

Nyakaana S, Abe EL, Arctander P, Siegismund HR. 2001. DNA evidence for elephant social behaviour breakdown in Queen Elizabeth National Park, Uganda. Anim Conserv 4: 231-237.

Okello JBA, Masembe C, Rasmussen HB, Wittenmyer G, Omondi P, Kahindi O, Muwanika VB, Arctander P, Douglas-Hamilton I, Nyakaana S, Siegismund HR. 2008. Population genetic structure of savannah elephants in Kenya: conservation and management implications. J Hered 99: 443-452.

PERHILITAN. 2017. Red List of mammals for Peninsular Malaysia Version 2.0. Kuala Lumpur. Department of Wildlife and National Parks (PERHILITAN) Peninsular Malaysia.

Rosli MKA, Zamzuriada AS, Syed-Shabthar SMF, Mahani MC, AbasMazni O, Md-Zain BM. 2011. Optimizing PCR conditions to amplify Cyt $b$, COI and 12S rRNA gene fragments of Malayan Gaur (Bos gaurus hubbacki) mtDNA. Genet Mol Res 10: 2554-2568.

Rozas J, Ferrer-Mata A, Sánchez-DelBarrio JC, Guirao-Rico S, Librado P, Ramos-Onsins SE, Sánchez-Gracia A. 2017. DnaSP 6: DNA sequence polymorphism analysis of large data sets. Mol Biol Evol 34: 3299-3302.

Rutten RGPA. 2008. Genetic management of wild Asian elephants (Elephas maximus) in Thailand. [Student research project]. Faculty of Veterinary Medicine, Nakorn Pathom Univ., Thailand.

Salman S, Nasharuddin O, Nawayai Y, Burhanuddin MN, Zafir A, Campos-Arceiz A. 2011. Current status of Asian elephants in Peninsular Malaysia. Gajah 35: 67-75.

Sripiboon S. 2013. Elephant conservation genetics: Elephant Research and Education Center. (Available at http://www.asianelephantresearch.com/about-elephant-conservationgenetics.php). 
Swofford DL. 2002. Phylogenetic analysis using parsimony and other methods version 4.0 beta version. Sinauer Associates, Sunderland.

Syed-Shabthar SMF, Rosli MKA, Mohd-Zin NAA, Romaino SMN, Fazly-Ann ZA, Mahani MC, Abas-Mazni O, Zainuddin R, Yaakop S, Md-Zain BM. 2013. The molecular phylogenetic signature of Bali cattle revealed by maternal and paternal markers. Mol Biol Rep 40: 5165-5176.

Zainudin R, Shukor MN, Norhayati A, Md-Zain BM, Mustafa AR. 2010.

Genetic structure of Hylarana erythraea (Amphibia: Anura: Ranidae) from Malaysia. Zool Stud 49: 688-702. 